\title{
(2) OPEN ACCESS \\ Challenges in the management of older patients with acute coronary syndromes in the COVID-19 pandemic
}

\author{
Ben Rowland, ${ }^{1,2}$ Vijay Kunadian (1) 1,2
}

\begin{abstract}
- Additional material is published online only. To view please visit the journal online (http://dx.doi.org/10.1136/ heartjnl-2020-317011).

${ }^{1}$ Translational and Clinical Research Institute, Faculty of Medical Sciences, Newcastle University, Newcastle upon Tyne, UK

${ }^{2}$ Cardiothoracic Centre, Freeman Hospital, Newcastle Upon Tyne, UK
\end{abstract}

\section{Correspondence to}

Dr Vijay Kunadian, Newcastle University Faculty of Medical Sciences, Newcastle upon Tyne NE1 7RU, UK:

vijay.kunadian@newcastle.ac.uk

Received 30 March 2020

Revised 1 May 2020

Accepted 2 May 2020

Published Online First

22 May 2020

\section{Check for updates}

(C) Author(s) (or their employer(s)) 2020. Re-use permitted under CC BY-NC. No commercial re-use. See rights and permissions. Published by BMJ.

To cite: Rowland B, Kunadian V. Heart

2020;106:1296-1301.

\section{ABSTRACT}

Ischaemic heart disease (IHD), in particular acute coronary syndrome (ACS), comprising ST-elevation myocardial infarction, non-ST-elevation myocardial infarction and unstable angina, is the leading cause of death worldwide. Age is a major predictor of adverse outcome following ACS. COVID-19 infection seems to escalate the risk in older patients with heart disease. Increasing odds of in-hospital death is associated with older age following COVID-19 infection. Importantly, it seems older patients with comorbidities such as cardiovascular disease (CVD), in particular IHD, diabetes and hypertension, are at the highest risk of mortality following COVID-19 infection. The evidence is sparse on the optimal care of older patients with ACS with lack of robust randomised controlled trials. In this setting, with the serious threat imposed by the COVID-19 pandemic in the context of rapidly evolving knowledge with much unknown, it is important to weigh the risks and benefits of treatment strategies offered to older patients. In cases where risks outweigh the benefits, it might not be an unreasonable option to treat such patients with a conservative or a palliative approach. Further evidence to elucidate whether invasive management is beneficial in older patients with ACS is required out-with the COVID-19 pandemic. Though it is hoped that the actual acute phase of COVID-19 infection will be short lived, it is vital that important clinical research is continued, given the long-term benefits of ongoing clinical research for patients with long-term conditions, including CVD. This review aimed to evaluate the challenges and the management strategies in the care of older patients presenting with ACS in the context of the COVID-19 pandemic.

\section{INTRODUCTION}

Ischaemic heart disease (IHD), in particular acute coronary syndrome (ACS), comprising ST-elevation myocardial infarction (STEMI), non-ST-elevation myocardial infarction (NSTEMI) and unstable angina, is the leading cause of death worldwide. ${ }^{1}$ Older patients are an increasing proportion of patients with myocardial infarction (MI) as population demographics in developed countries change and medical science advances. ${ }^{2}$ One of the major predictors of adverse outcome following ACS is age, yet patients aged $\geq 75$ years are often excluded or under-represented in clinical trials. ${ }^{34}$

COVID-19 infection seems to escalate the risk in older patients with cardiovascular disease (CVD), diabetes and hypertension. ${ }^{5}{ }^{6}$ There is increasing odds of in-hospital death associated with older age as a result of COVID-19 infection. ${ }^{5}$ Regardless of the COVID-19 pandemic, the optimal standardised care of ACS in older patients is not clear due to lack of robust evidence, clinicians' reluctance due to fear of complications (bleeding and comorbidities), perception of poor outcomes or low success rates in older patients, and patients presenting later after symptom onset or with an atypical presentation. ${ }^{7}$ The uncertainty in the optimal care of the older patients with ACS is further escalated in the context of the COVID-19 pandemic. This review aimed to evaluate the challenges and the management strategies in the care of older patients presenting with ACS in the context of the COVID-19 pandemic.

\section{CVD and COVID-19 in older adults}

In late 2019, a novel coronavirus, named COVID-19 or severe acute respiratory syndrome coronavirus 2 (SARS-CoV-2), emerged in Wuhan, China. It rapidly spread and the WHO declared it a pandemic on 11 March 2020. The virus is similar to the original severe acute respiratory syndrome (SARS) outbreak that appeared in the early 2000s. ${ }^{8}$ The two viruses are both likely zoonotic in origin, specifically derived from bats. ${ }^{9}$ Pangolin species appear to be a natural reservoir of SARS-CoV-2-like CoVs. ${ }^{10}$ The most common symptoms on admission are fever (98\%), cough (76\%), dyspnoea (55\%) and myalgias or fatigue (up to $44 \%$ ). ${ }^{11}$ Among patients with a mean age of 70 years, the most common presenting symptoms were shortness of breath (76\%), fever (52\%) and cough (48\%). ${ }^{12}$

SARS-CoV-2 uses the ACE2 receptor to enter the host cells. The spike protein in SARS-CoV-2 anchors to the S1 subunit of the ACE2 receptor. ${ }^{13}$ Viral cell entry requires the transmembrane serine protease 2 expressed on host cells to perform critical protein priming that leads to conformational changes, viral cell entry and cell infection. ACE2 is significantly expressed in the lungs, endothelium, heart, kidneys and gastrointestinal system. ${ }^{14}$ Those affected by cardiovascular comorbidities, such as diabetes or hypertension, are grossly overrepresented in severe cases of COVID-19. ${ }^{15}$ Since patients with these conditions have upregulated ACE2 receptors with possible hypersecretion of ACE2, these patients are particularly susceptible to COVID-19 infection (figure 1).

COVID-19 infection seems to have the following effects on older patients ${ }^{1}$ : poor outcomes in older patients and those with $\mathrm{CVD},{ }^{2}$ increased risk of CVD with COVID-19 infection or acute COVID-19 cardiovascular syndrome (ACovCS), ${ }^{3}$ indirect adverse consequences on CVD and MI. In 


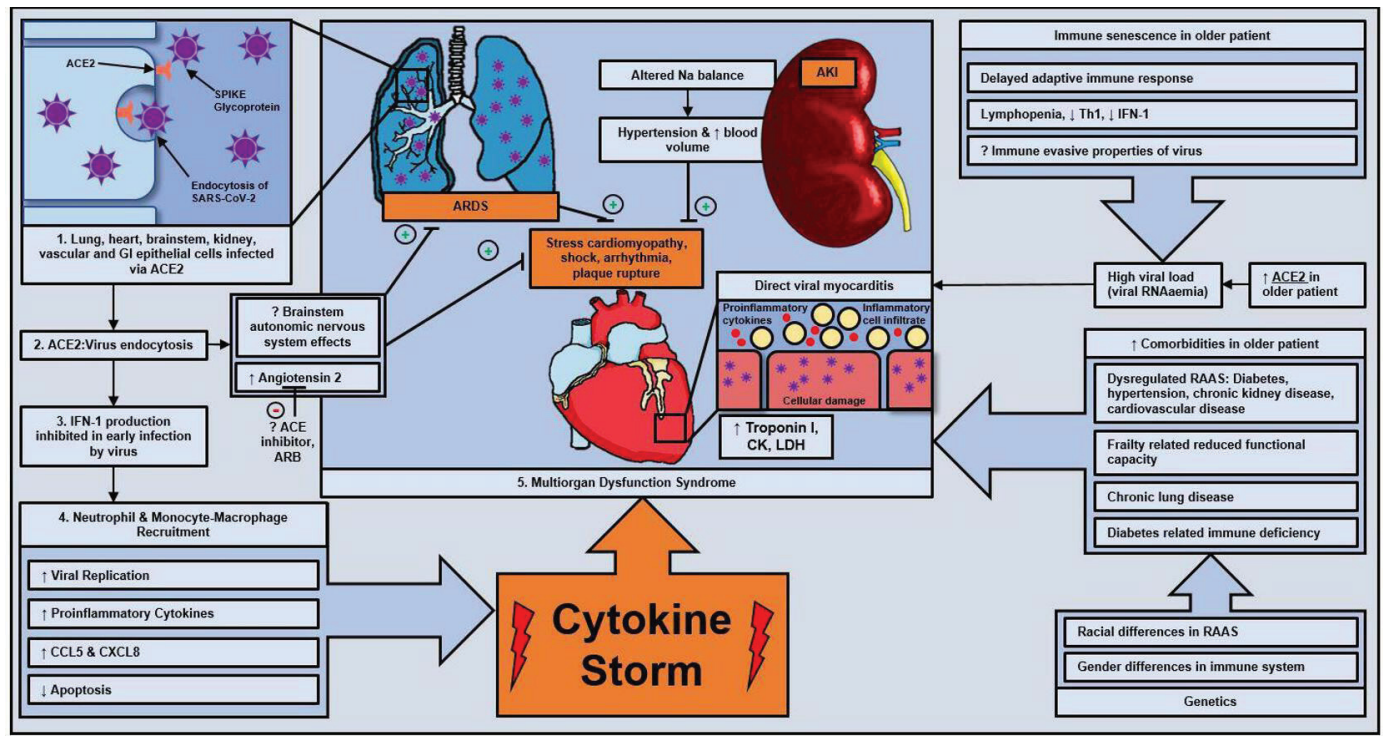

Figure 1 Hypothesised pathogenesis of acute cardiac injury in older patients. AKI, acute kidney injury; ARDS, acute respiratory distress syndrome; CCL5, chemokine ligand 5; CK, creatine kinase; CXCL8, C-X-C motif chemokine ligand 8; GI, gastrointestinal; IFN-1, interferon type 1; LDH, lactate dehydrogenase; $\mathrm{Na}$, sodium; RAAS; renin-angiotensin-aldosterone system; SARS-CoV-2, severe acute respiratory syndrome coronavirus 2; Th1, type 1 T-helper cell.

the context of the COVID-19 pandemic, patients can present with the typical type $1 \mathrm{MI}$ or ACovCS. ${ }^{16}$ Clinical judgement and COVID-19 clinical characteristics might help in the differentiation of the two conditions.

\section{Poor outcomes in older patients and those with CVD Morbidity}

COVID-19 is particularly deadly in older patients and those with pre-existing comorbidities such as respiratory disease or CVD. ${ }^{5} 1417$ Up to $86 \%$ of older adults with COVID-19 infection presented with comorbidities, and the most significant ones were chronic kidney disease (48\%), congestive heart failure (43\%), chronic obstructive pulmonary disease (33\%) and diabetes $(33 \%){ }^{12}$ Another study showed that hypertension (17\%), diabetes $(8 \%)$ and CVD (5\%) were the most prevalent comorbidities in those infected with COVID-19. ${ }^{18}$ Hypertension (relative risk (RR) 2.03, 95\% CI 1.54 to $2.68, \mathrm{p}<0.00001$ ) and cardiacerebrovascular (RR 3.30, 95\% CI 2.030 to $5.36, \mathrm{p}<0.00001$ ) disease were significantly more common in COVID-19-infected patients in intensive care unit. ${ }^{19}$

Intensive care admission and adult respiratory distress syndrome (ARDS)

Most older adults have some form of organ damage occurring due to SARS-CoV-2, including ARDS (71\%), acute kidney injury (AKI) (20\%), cardiac injury (33\%) and liver dysfunction $(15 \%)$, and $67 \%$ required vasopressor support for treatment. ${ }^{12}$ In a retrospective cohort study of 201 patients in Wuhan, ${ }^{17}$ old age increased the likelihood of developing ARDS (HR 3.26, $95 \%$ CI 2.08 to 5.11) and progressing from ARDS to death (HR $6.17,95 \%$ CI 3.26 to 11.67$)$. Patients who developed ARDS compared with those who did not were more likely to have comorbidities such as diabetes (19\% vs 5.1\%) and hypertension (27.4\% vs $13.7 \%)$. This may be more relevant to older women with ACS as they are more likely to have hypertension than men. $^{20}$

\section{Mortality}

In-hospital death following COVID-19 infection is associated with older age (OR 1.10, 95\% CI 1.03 to $1.17, \mathrm{p}=0.0043) .^{5}$ In the UK as per the Office of National Statistics, $24.6 \%$ of COVID-19 deaths were among those aged 75-84 years. ${ }^{21}$ In another study, case fatality rate (CFR) in patients aged over 60 years without comorbidities was $1.4 \%$, whereas the CFR was $13.2 \%$ for patients with CVD, $9.2 \%$ for patients with diabetes, $8.4 \%$ for patients with hypertension, $8 \%$ for patients with chronic respiratory disease and $7.6 \%$ for patients with cancer. ${ }^{22}$ One study on 46 fatal cases of SARS-CoV-2, in which $84 \%$ of patients were over the age of 60 years, found that diabetes is likely associated with increased mortality. ${ }^{11}$ High Sequential Organ Failure Assessment score (OR 5.65, 95\% CI 2.61 to $12.23, \mathrm{p}<0.0001)$ and $\mathrm{d}$-dimer $>1 \mu \mathrm{g} / \mathrm{mL}(\mathrm{OR}=18.42,95 \% \mathrm{CI}$ 2.64 to $128.55, \mathrm{p}=0.0033$ ) on admission were associated with poor prognosis. There is high mortality among patients who require mechanical ventilation. ${ }^{5}$

\section{Increased risk of CVD with COVID-19 infection}

It is well documented that pneumonia, including that from viral causes, may precipitate MI. ${ }^{23}$ Influenza pandemics characteristically have reported cardiac death as the the most common cause of death. ${ }^{24}$ The pathogenesis of ACovCS infection may involve direct viral myocarditis, stress cardiomyopathy or cytokine storm due to imbalance of type 1 and type 2 T-helper cells. ${ }^{14}$ Significantly higher levels of cytokines and chemokines were observed in infected patients, with severe cases showing evidence of high levels of proinflammatory cytokines. ${ }^{25}$ This cytokine storm may precipitate multiorgan dysfunction. Marked inflammatory response can also lead to the development of disseminated intravascular coagulopathy in critically ill patients, causing microvascular thrombosis in coronary circulation.

In a recent study, ${ }^{14} 5$ of the first 41 COVID-19-infected patients in Wuhan exhibited myocardial injury demonstrated by raised high-sensitivity cardiac troponin I (hs-cTnI). Some patients presented primarily with cardiac symptoms, such 
as chest pain, rather than fever and cough. In a report by the National Health Commission of China, $11.8 \%$ of patients who died of COVID-19 infection without underlying CVD exhibited evidence of 'substantial heart damage'. ${ }^{14}$ The rise in hs-cTnI appears to continue throughout the illness in patients who die. There is also evidence of some patients with COVID-19 experiencing substantial CVD acutely with acute cardiac injury (7.2\%), shock (8.7\%) and arrhythmia (16.7\%). ${ }^{26}$ Acute cardiac injury was significantly associated with intensive care patients (RR $13.48,95 \%$ CI 3.60 to $50.47, \mathrm{p}=0.0001){ }^{19}$

A cohort study of 416 patients observed that those with acute cardiac injury required non-invasive $(46.3 \%$ vs $3.9 \%, \mathrm{p}<0.001)$ or invasive mechanical ventilation $(22 \%$ vs $4.2 \%, \mathrm{p}<0.001)$ at a greater rate, and complications were more common, such as ARDS $(58.5 \%$ vs $14.7 \%, \mathrm{p}<0.001)$, AKI $(8.5 \%$ vs $0.3 \%$, $\mathrm{p}<0.001)$, electrolyte disturbance $(15.9 \%$ vs $5.1 \%, \mathrm{p}=0.003)$, hypoproteinaemia $(13.4 \%$ vs $4.8 \%, \mathrm{p}=0.01)$ and coagulation disorders $(7.3 \%$ vs $1.8 \%, \mathrm{p}=0.02) .{ }^{27}$ Importantly, myocardial injury is significantly associated with fatal outcome of COVID19-infected patients with CVD. ${ }^{28}$ Distinction between ACovCS and true ACS might be challenging in older patients.

\section{Long-term cardiovascular risks associated with COVID-19}

The long-term cardiovascular risks associated with COVID-19 are uncertain. ${ }^{26}$ Due to its similarity to SARS, there is a reasonable hypothesis that there might be extrapulmonary effects. This could be a future significant source of morbidity in older patients with ACS and may form part of treatment considerations. Studies of SARS survivors in long-term follow-up have shown significant morbidity. For example, a small study of 25 patients showed disrupted lipid metabolism (68\%), disrupted glucose metabolism (60\%) and cardiovascular system abnormalities (44\%) at follow-up. ${ }^{26}$ There is also a suggestion that those who have recovered may be at increased risk of MI. ${ }^{29}$ The exact nature and magnitude of any long-term cardiovascular morbidity of COVID-19 in older patients remain to be seen.

Indirect consequences of the COVID pandemic on CVD and MI During the COVID-19 pandemic, studies have shown approximately $40 \%$ reduction in STEMI activations in the cardiac catheterisation laboratories. ${ }^{30}$ Patients with STEMI may delay attending hospital after the onset of their symptoms. ${ }^{31}$ There is an increase in time to presentation, length of time from arrival at the hospital to successful percutaneous coronary intervention
(PCI) and arrival at the catheterisation lab to successful PCI, which might be due to fear of the pandemic or reluctance to be a burden on healthcare. More stringent infection control measures, such as detailed travel and contact history before transfer to the lab, more time taken to don protective gear in the lab and interventional cardiologists being inexperienced in performing PCI while wearing protective gear, also contribute to delays. Catheterisation labs operate under positive pressure and thus pose a particular risk of spreading the infection if the patient undergoing the procedure is infected. Clearly, protective measures vary between hospitals globally. Moreover, this may worsen as the crisis becomes more severe. For example, clinicians may not wish to take on the risk of complications with PCI as there may be no capacity within the hospital to go to critical care, for instance, or clinicians may wish to discharge their patient as quickly as possible to limit the chance of spread of infection.

\section{Management of older patients with ACS in the COVID-19 pandemic}

It seems prudent to employ COVID-19 pandemic-specific diagnosis and treatment protocols for the management of older patients with ACS. This is particularly important in the context of seemingly ubiquitous evidence showing older patients with cardiovascular morbidity are at increased risk, along with possible difficulties in healthcare resource provision, and probable changes in timing of presentation and treatment. How best to treat the older patients with ACS is already a complex question with limited evidence. In a pandemic situation that particularly targets the old and frail comorbid patient, the weighing up of the benefits of treatments and provision of care becomes both clinically and ethically challenging (figure 2).

\section{COVID-ACS protocols}

Many countries have adopted the public health approach of selfisolation/shielding, especially for the older population. This in itself poses a myriad of challenges-both in mental and physical health-and necessitates the implementation of some sort of systematic support for these patients. ${ }^{32}$ Those with fever or respiratory symptoms should first attend a fever outpatient clinic and then be admitted to an isolation ward for rapid testing, epidemiological history and body temperature reading. A recent study examined the ethics of allocation of limited resources in

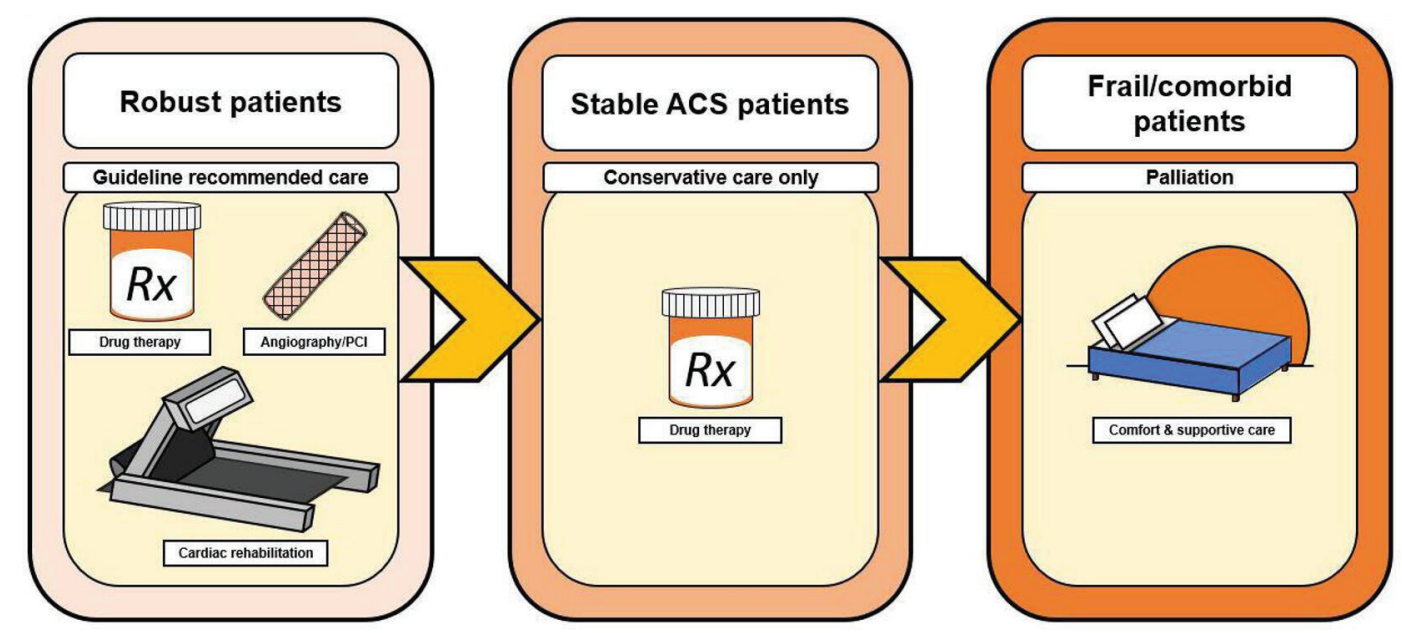

Figure 2 Individualised care of older patients. ACS, acute coronary syndrome; PCl, percutaneous coronary intervention; Rx, treatment. 
the COVID-19 pandemic and gave recommendations to aid clinician decision making. ${ }^{33}$

1. Apply consistently a utilitarian approach of maximising lives saved and life-years created.

2. Testing and therapeutics should go first to front-line healthcare workers.

3. For patients with similar prognoses, random allocation of resources rather than first-come first-served should be employed in the case of urgent need.

4. Prioritisation should be specific for an intervention and should reflect the evolving scientific literature, for example, vaccines going to the older patients first.

5. Participants in COVID-19 research should have increased priority.

6. There should be no difference in allocating resources between patients with COVID-19 and other patients.

\section{Acute COVID-19 cardiovascular syndrome}

Given the high rate of myocardial injury associated with COVID-19 infection, it is important to rule out $\mathrm{ACovCS}^{16}$ prior to consideration of ACS treatment. A proposed management of ACovCS is previously described. ${ }^{16}$ A recent document provides guidance on cardiac imaging during the COVID-19 pandemic. ${ }^{34}$ Coronary CT angiography can also exclude or confirm ACS in COVID-19 pneumonia where elevated troponins are common.

\section{ST-elevation myocardial infarction}

Primary percutaneous coronary intervention (PPCI) has drastically improved outcomes for all ages of patients with STEMI since its widespread adoption. ${ }^{35}$ There are very few randomised controlled trials (RCTs) that have evaluated the benefit of an invasive strategy in older patients with STEMI (online supplementary table 1). Current European Society of Cardiology guidelines recommend that there is no upper age limit for consideration for PPCI. ${ }^{36}$ Ongoing RCTs aim to evaluate the benefit of PPCI for STEMI in older patients. ${ }^{37} 38$ Among those with a definitive diagnosis of type 1 STEMI, in the context of lack of robust evidence in the care of the older patients with a diagnosis of STEMI, during the COVID-19 pandemic, PPCI should be considered for all patients. When PPCI poses logistical challenges, for example, time delay (time to PCI) of $>120 \mathrm{~min}^{36}$ thrombolysis might not be an unreasonable strategy in these patients.

\section{Non-STEMI}

During 15 years of follow-up of the FRagmin and Fast Revascularization during InStability in coronary artery disease (FRISC) II trial, an early invasive treatment strategy in patients with non ST elevation acute coronary syndrome (NSTE-ACS) postponed the occurrence of death or MI by an average of 18 months. The difference was mainly driven by postponement of new MI, whereas the early difference in mortality alone was not sustained over time. ${ }^{39}$ Older patients are a rapidly increasing proportion of patients with NSTE-ACS. ${ }^{40}$ Patients with NSTEMI are more likely to be older than patients with STEMI. ${ }^{41}$ However, smallsized RCTs in older patients with NSTEMI have shown mixed results, as summarised in online supplementary table 2. Frailty and comorbidities play an important role in the care of older patients with ACS and should be taken into consideration in deciding the treatment strategies. In a previous study, frailty was associated with a higher risk of major adverse cardiovascular event (MACE) (a composite of all-cause mortality, MI, stroke, unplanned revascularisation and major bleeding) at 1 year following invasive procedure for older patients with NSTEACS (HR 2.79, 95\% CI 1.28 to $6.08, \mathrm{p}=0.01$ ) compared with robust patients. ${ }^{42}$ Frailty is a significant predictor for all-cause mortality after PCI (HR 2.97, 95\% CI 1.56 to $5.66, \mathrm{p}=0.001) .{ }^{43}$ Cognitively impaired patients had a higher risk of MACE (a composite of all-cause mortality, MI, stroke, unplanned revascularisation and major bleeding) during follow-up $(p=0.047) .{ }^{44}$ Ongoing studies aim to evaluate the outcomes between invasive and conservatively managed groups in older patients, ${ }^{45}{ }^{46}$ taking into consideration frailty and other comorbidities. In the context of lack of robust evidence in the care of older patients with a definitive diagnosis of NSTEMI, during the COVID-19 pandemic, an initial conservative approach might not be an unreasonable strategy.

\section{Palliative care and advanced care planning}

For older patients who are frail and with multiple comorbidities, refraining from more active therapy may be the most humane and appropriate approach in many patients with provision of palliative care. ${ }^{47}$ Given the high mortality associated with older patients with ACS and its exacerbation with COVID-19 infection, it is important for the clinical care team to have highquality discussions where feasible about advance care planning and about goals of care with patients or their families. ${ }^{48}$

\section{Optimal cardiovascular secondary prevention therapy}

It is also important that patients with ACS are prescribed guidelinerecommended secondary prevention therapy. ${ }^{3649}$ Because of the pathology of how the virus infects its hosts, there has been some suggestion that ACE inhibitors (ACEIs) and angiotensin receptor blockers (ARBs) may exacerbate the virus. ${ }^{91450}$ However, this is likely unfounded based on the currently available data. ${ }^{50}$ Withdrawal of these medications would be ill advised due to their significant impact on reducing cardiovascular mortality, ${ }^{50}$ and in fact, a recent study suggests that inpatient use of ACEI/ARB was associated with lower risk of all-cause mortality compared with ACEI/ARB non-users. ${ }^{\text {w1 }}$ Rapid research to determine correlation with outcomes is necessary as these medications may be a valuable treatment modality or may be harmful to those already at greater risk. ${ }^{\text {w2 }}$ Careful evaluation of the need for antithrombotic therapy should also be considered in COVID-19-infected patients. ${ }^{\text {w3 }}$

Management of the catheter lab in the COVID-19 pandemic

Cardiology associations and societies have provided consensus documents on the management of the invasive procedure room and the personnel. ${ }^{\text {w-w7 }}$ Patients must wear a surgical mask while waiting preprocedure and postprocedure, there should be maximum coordination to minimise wait times, and all patients should have a detailed symptomatology, contact history and temperature reading before entering the lab. The consensus documents provides further specific information for protective equipment use, as well as handling and management of the patients during the procedure that may be a useful guide to the interventional cardiology team.

\section{Future directions}

Future such epidemics may emerge with a similar pattern of zoonotic origin, such as Middle East respiratory syndrome, SARS and COVID-19. Ongoing wildlife-human interaction practices may continue to pose a significant public health risk in the future and was predicted a 'time bomb' in a 2007 coronavirus review. ${ }^{\text {w8 }}$ 
The COVID-19 pandemic emphasises the need for the rapid development and implementation of clear strategies to deal with such crises in the care of patients with heart disease. Of note during this COVID-19 pandemic crisis, many cardiovascular clinical research studies have been paused or suspended. Though it is hoped that the actual acute phase of COVID-19 infection will be short lived, it is vital that important clinical research is continued, given the long-term benefits of ongoing clinical research for patients with long-term conditions including CVD. ${ }^{\mathrm{w} 9}$

\section{CONCLUSION}

The evidence is sparse on the optimal care of older patients with ACS with lack of robust RCTs. In this setting, with a serious threat imposed by the COVID-19 pandemic in the context of rapidly evolving knowledge with much unknown, it is important to weigh the risks and benefits of treatment strategies offered to patients. In cases where risks outweigh the benefits, it might not be an unreasonable option to treat such patients with a conservative or a palliative approach. Further evidence to elucidate whether invasive management is beneficial in older patients with ACS is required. Importantly, resumption of ongoing research activities to address these gaps is required once of course the acute phase of COVID-19 pandemic challenges pass.

Additional references can be found in the online supplementary file.

Acknowledgements VK is supported by the British Heart Foundation Clinical Study Grant (CS/15/7/316), Newcastle NIHR Biomedical Research Centre and Institutional Research Grant from Astra Zeneca (ISSBRIL0303).

Contributors BR wrote the first draft and was involved in revisions. VK came up with the concept, made substantial revisions and created the figures.

Funding The authors have not declared a specific grant for this research from any funding agency in the public, commercial or not-for-profit sectors.

Competing interests None declared.

Patient and public involvement Patients and/or the public were not involved in the design, or conduct, or reporting, or dissemination plans of this research.

Patient consent for publication Not required.

Provenance and peer review Not commissioned; externally peer reviewed.

Open access This is an open access article distributed in accordance with the Creative Commons Attribution Non Commercial (CC BY-NC 4.0) license, which permits others to distribute, remix, adapt, build upon this work non-commercially, and license their derivative works on different terms, provided the original work is properly cited, appropriate credit is given, any changes made indicated, and the use is non-commercial. See: http://creativecommons.org/licenses/by-nc/4.0/.

\section{ORCID iD}

Vijay Kunadian http://orcid.org/0000-0003-2975-6971

\section{REFERENCES}

1 Organisation WH. Available: http://www.who.int/healthinfo/survey/ageingdefnolder/ en/

2 MINAP. 2020.

3 Sinclair H, Batty JA, Qiu W, et al. Engaging older patients in cardiovascular research: observational analysis of the ICON-1 study. Open Heart 2016;3:e000436.

4 Veerasamy $M$, Edwards R, Ford $G$, et al. Acute coronary syndrome among older patients: a review. Cardiol Rev 2015;23:26-32.

5 Zhou F, Yu T, Du R, et al. Clinical course and risk factors for mortality of adult inpatients with COVID-19 in Wuhan, China: a retrospective cohort study. Lancet 2020:395:1054-62.

6 Remuzzi A, Remuzzi G. COVID-19 and Italy: what next? The Lancet 2020;395:1225-8.

7 Simms AD, Batin PD, Kurian J, et al. Acute coronary syndromes: an old age problem. J Geriatr Cardiol 2012;9:192-6.

8 W-j G, Z-y N, Hu Y, et al. Clinical characteristics of coronavirus disease 2019 in China. New England Journal of Medicine 2020.
9 Clerkin KJ, Fried JA, Raikhelkar J, et al. Coronavirus disease 2019 (COVID-19) and cardiovascular disease. Circulation; 58.

10 Zhang T, Wu Q, Zhang Z. Probable Pangolin origin of SARS-CoV-2 associated with the COVID-19 outbreak. Curr Biol 2020;30:1346-51.

11 Huang C, Wang Y, Li X, et al. Clinical features of patients infected with 2019 novel coronavirus in Wuhan, China. Lancet 2020;395:497-506.

12 Arentz M, Yim E, Klaff L, et al. Characteristics and outcomes of 21 critically ill patients with COVID-19 in Washington state. JAMA 2020. doi:10.1001/jama.2020.4326

13 Zhang H, Penninger JM, Li Y, et al. Angiotensin-Converting enzyme 2 (ACE2) as a SARS-CoV-2 receptor: molecular mechanisms and potential therapeutic target. Intensive Care Med 2020;46:586-90.

14 Zheng Y-Y, Ma Y-T, Zhang J-Y, et al. COVID-19 and the cardiovascular system. Nat ReV Cardiol 2020;17:259-60.

15 Li B, Yang J, Zhao F, et al. Prevalence and impact of cardiovascular metabolic diseases on COVID-19 in China. Clinical research in cardiology : official journal of the German Cardiac Society 2020:1-8.

16 Hendren NS, Drazner MH, Bozkurt B, et al. Description and proposed management of the acute COVID-19 cardiovascular syndrome. Circulation;0.

17 Wu C, Chen X, Cai Y, et al. Risk factors associated with acute respiratory distress syndrome and death in patients with coronavirus disease 2019 pneumonia in Wuhan, China. JAMA Intern Med 2020. doi:10.1001/jamainternmed.2020.0994

18 Yang JZY, Gou X, Pu K, et al. Prevalence of comorbidities in the novel Wuhan coronavirus (COVID-19) infection: a systematic review and meta-analysis. International Journal of Infectious Diseases.

19 Li B, Yang J, Zhao F, et al. Prevalence and impact of cardiovascular metabolic diseases on COVID-19 in China. Clin Res Cardiol 2020;109:531-538.

20 Thang ND, Karlson BW, Karlsson T, et al. Characteristics of and outcomes for elderly patients with acute myocardial infarction: differences between females and males. Clin Interv Aging 2016;11:1309-16.

21 ONS. Deaths involving COVID-19, England and Wales: deaths occurring in March 2020, 2020.

22 WHO. WHO-China joint mission on coronavirus disease 2019, 2020.

23 Kwong JC, Schwartz KL, Campitelli MA, et al. Acute myocardial infarction after Laboratory-Confirmed influenza infection. N Engl J Med 2018;378:345-53.

24 Yamauchi-Takihara K. What we learned from pandemic H1N1 influenza A. CardiovasC Res 2011;89:483-4.

25 Rothan HA, Byrareddy SN. The epidemiology and pathogenesis of coronavirus disease (COVID-19) outbreak. J Autoimmun 2020;109:102433.

26 Xiong T-Y, Redwood S, Prendergast B, et al. Coronaviruses and the cardiovascular system: acute and long-term implications. Eur Heart J 2020. doi:10.1093/eurheartj/ ehaa231

27 Shi S, Qin M, Shen B, et al. Association of cardiac injury with mortality in hospitalized patients with COVID-19 in Wuhan, China. JAMA Cardio/ 2020. doi:10.1001/ jamacardio.2020.0950

28 Guo T, Fan Y, Chen M, et al. Cardiovascular implications of fatal outcomes of patients with coronavirus disease 2019 (COVID-19). JAMA Cardiology 2020

29 Driggin E, Madhavan MV, Bikdeli B, et al. Cardiovascular considerations for patients, health care workers, and health systems during the coronavirus disease 2019 (COVID-19) pandemic. J Am Coll Cardiol 2020;27204. doi:10.1016/j. jacc.2020.03.031

30 Garcia S, Albaghdadi MS, Meraj PM, et al. Reduction in ST-segment elevation cardiac catheterization laboratory activations in the United States during COVID-19 pandemic. J Am Coll Cardiol 2020;27259. doi:10.1016/j. jacc. 2020.04.011

31 C-CF T, Cheung K-S, Lam S, et al. Impact of coronavirus disease 2019 (COVID-19) outbreak on ST-Segment-Elevation myocardial infarction care in Hong Kong, China. Circulation: Cardiovascular Quality and Outcomes;0:CIRCOUTCOMES.120.006631.

32 Armitage R, Nellums LB. COVID-19 and the consequences of isolating the elderly. The Lancet Public Health.

33 Emanuel EJ, Persad G, Upshur R, et al. Fair allocation of scarce medical resources in the time of Covid-19. N Engl J Med 2020. doi:10.1056/NEJMsb2005114

34 Skulstad H, Cosyns B, Popescu BA, et al. COVID-19 pandemic and cardiac imaging: EACVI recommendations on precautions, indications, prioritization, and protection for patients and healthcare personnel. Eur Heart J Cardiovasc Imaging 2020. doi:10.1093/ehjci/jeaa072

35 Global Use of Strategies to Open Occluded Coronary Arteries in Acute Coronary Syndromes (GUSTO Ilb) Angioplasty Substudy Investigators. A clinical trial comparing primary coronary angioplasty with tissue plasminogen activator for acute myocardial infarction. N Engl J Med 1997;336:1621-8.

36 Ibanez B, James $\mathrm{S}$, Agewall $\mathrm{S}$, et al. Esc guidelines for the management of acute myocardial infarction in patients presenting with ST-segment elevation: the task force for the management of acute myocardial infarction in patients presenting with ST-segment elevation of the European Society of cardiology (ESC). European Heart Journal 2017:2017:119-77.

37 Van de Werf F. Strategic reperfusion in elderly patients early after myocardial infarction (STREAM-2). estimated, 2022.

38 Kong D. Study of access site for enhancing PCI in STEMI for seniors (safe STEMI for seniors). estimated, 2022. 
39 Wallentin L, Lindhagen L, Ärnström E, et al. Early invasive versus non-invasive treatment in patients with non-ST-elevation acute coronary syndrome (FRISCII): 15 year follow-up of a prospective, randomised, multicentre study. Lancet 2016;388:1903-11.

40 Dai X, Busby-Whitehead J, Alexander KP. Acute coronary syndrome in the older adults. J Geriatr Cardiol 2016;13:101-8.

41 Ishihara M, Fujino M, Ogawa H, et al. Clinical Presentation, Management and Outcome of Japanese Patients With Acute Myocardial Infarction in the Troponin Era - Japanese Registry of Acute Myocardial Infarction Diagnosed by Universal Definition (J-MINUET). Circ J 2015;79:1255-62.

42 Batty J, Qiu W, Gu S, et al. One-Year clinical outcomes in older patients with non-ST elevation acute coronary syndrome undergoing coronary angiography: an analysis of the ICON1 study. Int J Cardiol 2019;274:45-51.

43 Tse G, Gong M, Nunez J, et al. Frailty and mortality outcomes after percutaneous coronary intervention: a systematic review and meta-analysis. J Am Med Dir Assoc 2017; 18:1097.e1-1097.e10.

44 Gu SZ, Beska B, Chan D, et al. Cognitive decline in older patients with non- ST elevation acute coronary syndrome. J Am Heart Assoc 2019;8:e011218.
45 Sanchis J. Invasive versus conservative strategy in frail patients with NSTEMI: the MOSCA-FRAIL clinical trial study design.

46 Kunadian V. The British heart Foundation SENIOR-RITA trial (SENIOR-RITA). estimated, 2029.

47 Erne P, Radovanovic D, Seifert B, et al. Outcome of patients admitted with acute coronary syndrome on palliative treatment: insights from the nationwide AmiS plus registry 1997-2014. BMJ Open 2015;5:e006218.

48 Curtis JR, Kross EK, Stapleton RD. The importance of addressing advance care planning and decisions about do-not-resuscitate orders during novel coronavirus 2019 (COVID-19). Jama 2020.

49 Roffi M, Patrono C, Collet J-P, et al. Esc guidelines for the management of acute coronary syndromes in patients presenting without persistent ST-segment elevation: Task force for the management of acute coronary syndromes in patients presenting without persistent ST-segment elevation of the European Society of cardiology (ESC). European Heart Journal 2015;2016:267-315.

50 Kuster GM, Pfister 0, Burkard T, et al. SARS-CoV2: should inhibitors of the renin-angiotensin system be withdrawn in patients with COVID-19? Eur Heart J 2020;426. 